$$
\begin{aligned}
& \text { Ricue } U \text {. } \\
& N S G-6
\end{aligned}
$$

Easy Glide in Molybdenum Crystals

Only during the last few years has easy glide been observed in body-centered cubic crystals. Keh ${ }^{(1)}$ and Jaoul and Gonzales(2) working with iron crystals observed stress-strain curves which displayed three stages of work hardening. Mitcheil et ai. (3) studied the three regions of work hardening in niobium and found that the stages became more distinct the greater the degree of purity and the lower the strain rate. Easy glide was favored by single slip on the (110)[1i1] system. Mitchell and Spitzig(4) found almost identical conditions for the occurrence of easy glide in tantalum.

Results obtained recently in this laboratory revealed the occurrence of easy glide in molybdenum crystals, a typical example of which is given in Fig. 1. The results were obtained by using direct shear on the (110) [1i1] system of $0.125^{\prime \prime}$ diameter electron-beam zone-refined molydbenum crystals, using a testing method similar to that of Parker and Washburn (5). The activation volume, also shown in Fig. $\left.1 ., \mathrm{V}^{*}=\mathrm{kT}^{\mathrm{T}} \frac{\Delta \ln \dot{\gamma}}{\Delta \tau}\right)_{\mathrm{T}, \gamma}$, was determined by sudden changes in the strain rate, $\dot{\gamma}$, by a factor of 5 , and from observation of the resulting change in shear stress, $\Delta \tau$, at constant temperature.

Easy glide was detected only at temperatures greater than $300^{\circ} \mathrm{K}$ for a shear-strain rate of $4 \times 10^{-5} \mathrm{sec}^{-1}$. At higher
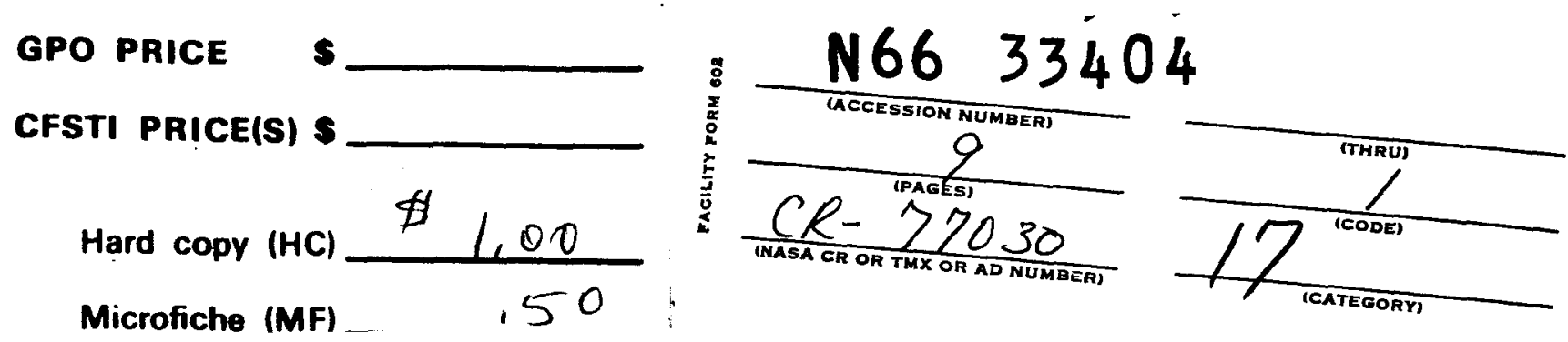
strain rates a greater temperature was required for the observation of easy glide. The extent of the easy-glide region under the aforementioned conditions depended markedly on the degree of purity of the crystals. In general, only crystals with a resistance ratio, $\frac{\mathrm{R}\left(273^{\circ} \mathrm{K}\right)}{\mathrm{R}\left(4.2^{\circ} \mathrm{K}\right)}$, of better than 2500 gave any indication of easy glide. The slope of the stress-strain curves in the easy-glide region, $\frac{d \tau}{d \gamma}$, was about $\frac{G}{3000}$, depending, however, on temperature and strain rate. The slope in region II was about $\frac{G}{900}$. This compares with $\frac{G}{600}$ obtained by Mitchell et al. $(3,4)$ with niobium and tantalum.

It has been suggested ${ }^{(3)}$ that the easy-glide stage in niobium prevails as long as the edge dislocations are able to move over large distances, i.e., until secondary slip begins to block the slip lines. A similar situation might prevail in molybdenum. The sensitivity of easy glide to impurities in molybdenum might be attributed to the increased flow stresses in the impure material which enhance secondary slip. This hypothesis is being studied with the help of electron microscopy. The significance of the plateau in the activation-volume curve in the easy glide region, Fig. 1 ., is also being investigated. 


\section{Caption to Figure}

Fig. 1. Flow stress and activation volume of molybdenum crystal exhibiting easy glide when tested in direct shear. 


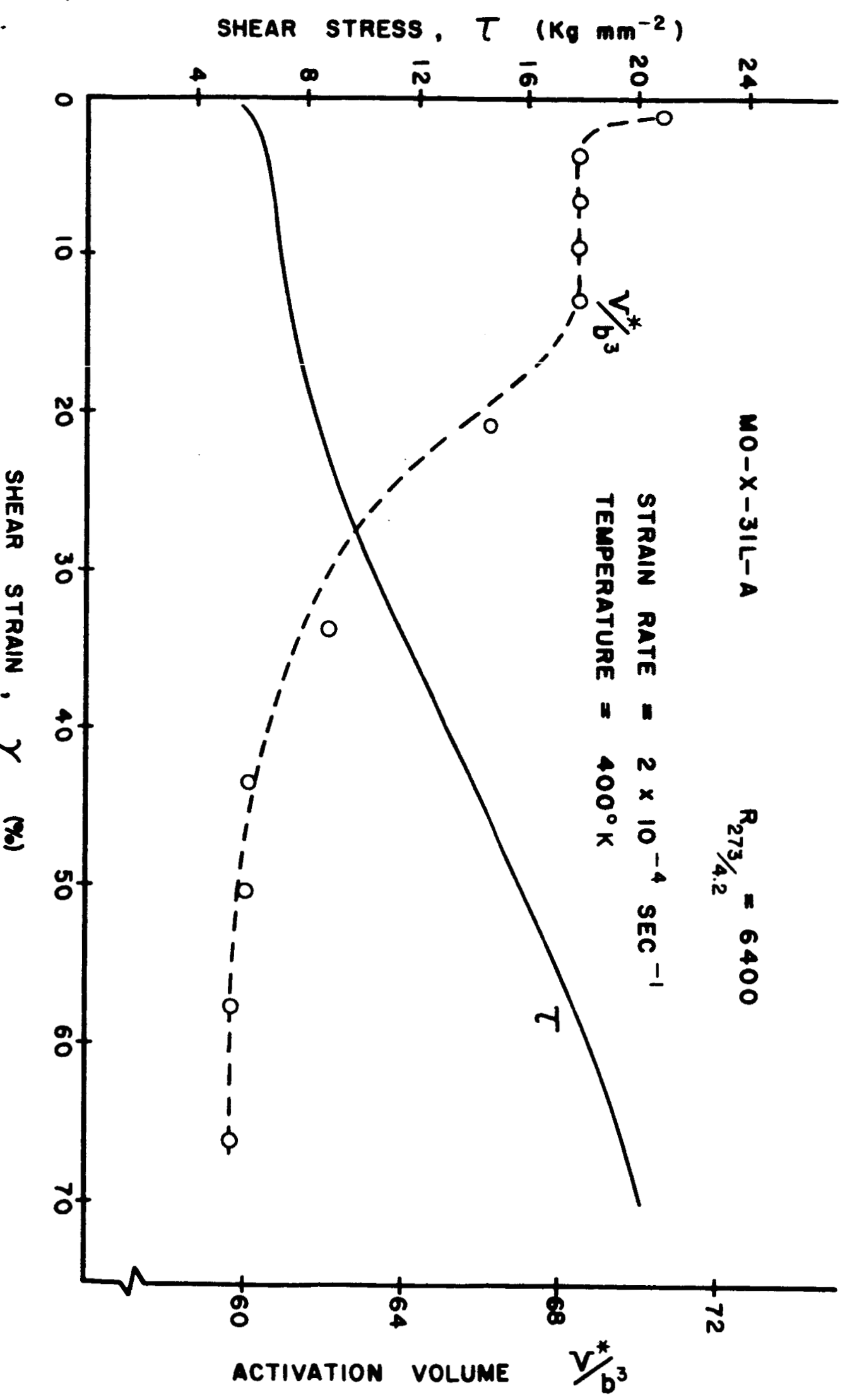




\section{References}

1. A. S. Keh, Phil. Mag. 12, 9 (1965)

2. D. Jaoul and D. Gonzalez, Jn1. Mech. Phys. Solids 12, 16 (1961)

3. T. E. Mitchell, R. A. Foxall, and P. B. Hirsch, Phil Mag. 8, 1895 (1963)

4. T. E. Mitchell and W. A. Spitzig, Acta Met. 13, 1169 (1965).

5. E. R. Parker and J. Washburn, Modern Research Techniques in Physical Metallurgy, p. 186, ASM, Cleveland (1953). 